\title{
An Empirical Study of the Influence of Formative Assessment on Classroom Environment of College English Reading, Writing and Translating
}

\author{
Mingxia Zheng and Qinghua Fang \\ Wuhan University of Science and Technology, Wuhan, Hubei, China \\ 715463133@qq.com,312852383@qq.com
}

\begin{abstract}
Keywords: Classroom environment; Formative assessment; 50\%; College English Reading, Writing and Translating; Influence differences
\end{abstract}

\begin{abstract}
The study investigated the students' perception of classroom environment of English Reading, Writing, Translating class after increasing the share of formative assessment to 50\% through quantitative and qualitative analysis, and explored whether there are influence differences between different level classes and students of three-level proficiency. Results demonstrate that: 1) students' overall perception of classroom environment has improved, especially in the "Classroom Involvement"; 2) there are influence differences between two classes, significant difference presented on five factors, namely, "Students' Cooperation", "Students' Collaboration", "Students' Responsibility", "Equality" and "Teachers' innovation"; 3) after increasing the ratio of formative assessment, the influence of high and medium-level group is positive on all factors while the low-level group show negative influence in "Students Cooperation"; "Teachers' Leading"; "Equality" and "Teacher' innovation".
\end{abstract}

\section{Research Background}

Guided by College English Curriculum Requirements, most universities gave priority to develop students' ability of listening and speaking, while neglected their reading and writing ability which have been remaining the weak points of the Chinese English learners for a long time. Therefore, Cai clearly pointed out that universities should endeavor to improve students' reading and writing ability[1]. However, there exists many problems in current English Reading, Writing and Translating class, for example, students listen to teachers passively in class; classroom involvement and interactions are insufficient; students lack learning interests in tedious classroom atmosphere and so on[2].What's more, without the real language environment needed for natural acquisition, so the classroom environment plays an important role in language learning for it is the main place for learning. Sun also pointed out that the ideal foreign language learning environment should provide students with adequate opportunity to use English and create an environment in which students can communicate in English and improve their English application ability through problem solving and task accomplishment[3]. Consequently, it is imperative to improve the current classroom environment to enhance teaching quality. The author try to increase the share of formative assessment from $30 \%$ to $50 \%$, which means that students need to pay more attention to their usual performance and autonomous learning instead of only working hard before final examination.

Classroom environment refers to both students' and teachers' perception to their classroom, which is a key factor in students' development process and also an element can not be ignored by any educators who want to improve teaching quality[3]. Classroom environment includes physical and humanistic environment which refers to the social psychological environment created by both students and teachers in classroom[4]. As the physical environment is relatively more stable than social psychological environment, the scholars at home and abroad have paid much attention to social psychological environment. In western countries, the studies on classroom environment focus on the measurement instruments which are used to explore students' perception to their classroom environment and the relationship between classroom environment and student' attitude, motivation and outcomes[5][6][7]. But these studies were mainly conducted in chemistry, math or biology 
classroom of primary or middle schools. The empirical studies on English class is relatively insufficient now, let alone on the English Reading, Writing and Translating class. At this moment, domestic studies on classroom environment are turning from introduction and review of westerners' findings on classroom environment[8] to empirical studies. Sun studied students' perception features of College Comprehensive English classroom and Oral classroom through the questionnaire designed by herself. The following studies mostly concentrated on the influence of classroom environment on students' classroom behavior [9]; the learning outcomes[10]; autonomous leaning ability [11] and teaching effectiveness [12]. From the above review, it is clear that positive and harmonious classroom environment have certain impact on students' learning and psychological development[13], so finding ways to optimize classroom environment should be put in priority. The current study focuses on the social psychological classroom environment, namely the interactions between teacher and student or peers; teachers' and students' personality characteristics; psychological conditions and psychological atmosphere in classroom[14].

\section{Formative Assessment and Assessment Standard}

Formative Assessment. Formative Assessment was first proposed by the philosopher of the University of Chicago, Scarlett, in his book "Evaluation Methodology" in 1976. Subsequently, the American educator Bloom divided teaching evaluation into diagnostic evaluation, formative assessment and summative assessment and emphasized the importance of formative assessment. He believes that the formative assessment is conducted in the teaching process, which is mainly to improve the effectiveness and quality of teaching by providing timely feedback to students. Formative assessment stresses students' knowledge, skills and attitudes. This kind of student-oriented formative evaluation arouses more and more scholars' attention, Weirt argues that teachers should make full use of formative evaluations and effectively adjust the behavior of all aspects of teaching and students. In addition, Harlen \& James believes that formative evaluation helps to identify the gap between the student's current proficiency and learning goals [15]and promote student achievement progress [16]. The Chinese scholars also have paid much attention to the influence of formative assessment. Guo Qian thinks that the formative assessment can promote students' English autonomous learning ability[17]. As the theory of formative assessment develops, more and more empirical research shows that the use of formative assessment in college English classroom can improve the effectiveness of teaching [18], stimulate students' learning motivation and promote the cooperative relationship between teachers and students [19]. Therefore, there are reasons to believe that the classroom environment of English Reading, Writing, Translating can be improved by increasing the share of formative assessment to $50 \%$.

The Assessment Standard. As the ratio of formative assessment increases, we made a little adjustment of the assessment standard. It mainly includes five factors: attendance(5\%), preview $(5 \%)$; classroom performance $(15 \%)$; homework $(15 \%)$; usual test $(10 \%)$. In order to help students develop the habit of preview, the teacher will assign some tasks which are related to the content they will learn in next class, for example, preview the material; the important words and expressions and the text structure. Classroom performance is evaluated from such aspects as topic discussion; role play; answering questions and group work. The aim is to arouse their interest in class and make them involve in class instead of just listening to the teacher. Homework consists of writing; translating and presentation, some of them are individual work and others are group work which is mainly to promote their autonomous learning ability and cooperation awareness. In addition, the teacher will evaluate students' mastery degree of each unit by several usual tests.

\section{Research Methodologies}

Research Questions. To identify the influence of 50\% formative assessment on the classroom environment of College English Reading, Writing and Translating. There are three questions in this study:

Whether the classroom environment of English Reading, Writing and Translating has been 
improved after increasing the ratio of formative assessment to $50 \%$ ?

Are there influence differences between the high English proficiency class and the lower one?

Are there any influence differences that $50 \%$ formative assessment exerts on College English Reading, Writing and Translating classroom environment for students of different levels?

Research Subject. The subjects consist of 61 non-English major sophomores from 2 classes of WuHan University of Science and Technology. The questionnaire is distributed to students at the beginning of the first semester in sophomore to get the pretest data of the traditional classroom and the final examination scores of English Reading, Writing and Translating in last semester. Based on their final examination scores, they are divided into two groups, namely class A (rank 26/155)and class B(rank 132/155). There are 30 students in class A and 31 students in class B. Besides, students whose score above 80 belong to the high-level group; scores between 60 and 79 belong to the medium-level group and scores below 60 belong to the low-level group.

Research Instrument. Two instruments are used to obtain data for the study, including "College English of Reading, Writing and Translating Classroom Environment Inventory" (CERWTCEI) and interview.

Questionnaire. The questionnaire used in the study is designed on the basis of Sun Yunmei's the Comprehensive English Class Inventory(CCECEI) and Fraser's WIHIC(What is Happening In the class) and takes into account the characteristics of English Reading, Writing and Translating class and formative assessment. Finally, CERWTCEI is designed to study the classroom environment features of English Reading, writing and Translating class. The two questionnaire are proved to have high reliability and validity as they have been used in various classroom environment, more importantly, the CCECEI is designed for the Chinese College English classroom environment. Therefore, the reliability, validity and suitability of CERWTCEI can be guaranteed theoretically. Then the reliability test is also conducted and the results are shown in the following table, from which we can see that the questionnaire's reliability reaches 0.963 and the Cronbach' Alpha of all factors in the questionnaire is above 0.7, which stands for a good internal consistency of this questionnaire. Besides, the result of Factor Analysis shows good internal dependency of all factors for the KMO is 0.903 and the Bartlett is 636.284( $\mathrm{p}<0.01)$.

Interview Questions. In the later stage of this semester, we made a interview to some students who are at the level of high, medium and low respectively to understand how they feel in this new class mode. The questions are as follows:

1. Do you think there are differences between this semester and last semester? If there are, what are they?

2. Have you got help from teacher and classmates?

3. Did your willing to participate in classroom become stronger?

4. Do you want to continue this class mode?

Research Procedure. At the beginning of the first semester in sophomore, the questionnaire is distributed to students to get the pretest data. During the experiment process, the teaching assistant made a interview to several students. At the end of the semester, the teaching assistant distributed the questionnaire to students for getting the post-test data. All data is analyzed by SPSS 20.

\section{Data Analysis and Discussion}

The data are analyzed by SPSS 20 . In order to identify the influence exerted by $50 \%$ formative assessment, we compared the pretest data and the post-test data by the Paired Sample T-test. 
Table 1. Paired Sample T-test of difference between pretest and post-test data

\begin{tabular}{|l|l|l|l|l|l|l|l|l|}
\hline $\begin{array}{c}\text { Factors of Classroom } \\
\text { Environment }\end{array}$ & $\begin{array}{c}\text { Mean } \\
\text { (before ) }\end{array}$ & $\begin{array}{c}\text { Std. } \\
\text { Deviation }\end{array}$ & $\begin{array}{c}\text { Mean } \\
\text { (after ) }\end{array}$ & $\begin{array}{c}\text { Std. } \\
\text { Deviation }\end{array}$ & $\begin{array}{c}\text { Mean } \\
\text { Difference }\end{array}$ & t & Sig & df \\
\hline Student's Collaboration & 3.256 & .5325 & 3.652 & .6404 & $-.3960^{*}$ & -10.724 & .000 & 60 \\
\hline Student's Cooperation & 3.277 & .4921 & 3.667 & .7108 & $-.3904^{*}$ & -8.938 & .000 & 60 \\
\hline Teacher's Support & 3.429 & .5864 & 3.693 & .6584 & $-.2644^{*}$ & -6.784 & .000 & 60 \\
\hline Teacher's Leading & 3.365 & .5387 & 3.485 & .5885 & $-.1197^{*}$ & -3.821 & .000 & 60 \\
\hline Classroom Involvement & 3.203 & .5797 & 3.609 & .6633 & $-.4059^{*}$ & -9.069 & .000 & 60 \\
\hline Student's Responsibility & 3.403 & .5685 & 3.670 & .7077 & $-.2671^{*}$ & -5.914 & .000 & 60 \\
\hline Task Orientation & 3.311 & .5828 & 3.667 & .7243 & $-.3557^{*}$ & -7.982 & .000 & 60 \\
\hline Equality & 3.408 & .5368 & 3.514 & .6379 & $-.1064^{*}$ & -4.074 & .000 & 60 \\
\hline Teacher's Innovation & 3.253 & .6313 & 3.616 & .7522 & $-.3639^{*}$ & -7.765 & .000 & 60 \\
\hline
\end{tabular}

From the means, it is clear that students' overall perception to classroom environment are improved on all factors after increasing the share of formative assessment to 50\%, which indicates that $50 \%$ formative assessment has a positive affect on the classroom environment of English Reading, Writing, Translating class. In addition, inspections of the mean difference between two classes indicates that the improvement in "Classroom Involvement" is the greatest and the improvement in "Equality" is the least. The results show that students' willing to participate in classroom activities has improved significantly because they can get scores by usual performance instead of just rely on the final examination. However, because of the limited class time, the size of class, different language proficiency and personalities, some students may fail to grasp chances to express themselves and find it difficult to accomplish some tasks in class.

Table 2. Independent Sample T-test for differences between Class A and Class B

\begin{tabular}{|c|c|c|c|c|c|c|c|c|}
\hline \multirow{2}{*}{$\begin{array}{l}\text { Factors of Classroom } \\
\text { Environment }\end{array}$} & \multicolumn{2}{|c|}{ Class A $(\mathrm{N}=30)$} & \multicolumn{2}{|c|}{ Class $\mathrm{B}(\mathrm{N}=31)$} & \multirow{2}{*}{$\begin{array}{c}\text { Mean } \\
\text { Difference }\end{array}$} & \multicolumn{3}{|c|}{ T-test } \\
\hline & Mean & $\begin{array}{c}\text { Std. } \\
\text { Deviation }\end{array}$ & Mean & $\begin{array}{c}\text { Std. } \\
\text { Deviation }\end{array}$ & & $\mathrm{t}$ & $\mathrm{df}$ & Sig. \\
\hline Student's Collaboration & .497 & .2615 & .296 & 2711 & $.2012 *$ & 2.949 & 59 & .005 \\
\hline Student's Cooperation & .505 & .3767 & .280 & .2643 & $.2253^{*}$ & 2.696 & 51.841 & .009 \\
\hline Teacher's Support & .334 & 2967 & .197 & .3011 & .1376 & 1.797 & 59 & .077 \\
\hline Teacher's Leading & .179 & .2689 & .062 & .2068 & .1174 & 1.915 & 59 & .060 \\
\hline Classroom Involvement & .458 & .3613 & .355 & .3360 & .1025 & 1.148 & 59 & .256 \\
\hline Student's Responsibility & .371 & .4330 & .166 & .2151 & $.2045^{*}$ & 2.348 & 42.182 & .022 \\
\hline Task & .383 & .3851 & .329 & .3122 & .0543 & .604 & 59 & .547 \\
\hline Equality & .198 & .1929 & 017 & .1749 & $.1809^{*}$ & 3.840 & 59 & .000 \\
\hline Teacher's Innovation & .400 & .5630 & .130 & .3410 & $.2710 *$ & 2.282 & 47.432 & .028 \\
\hline
\end{tabular}

Class Differences. In order to identify whether there are class differences after increase the ratio of formative assessment, we compared the pretest and post-test data of two classes respectively, getting the table 2. The data indicates that students' overall perception improved after increasing the share of formative assessment. From the means, for students in class A, improvement in "Student's Cooperation" is the most, and the improvement in "Teacher's Leading" is the least. What's more, "Classroom Involvement" and "Student's Collaboration" also improved a lot, which indicates that 
students from class A behavior more positively in classroom activities and they have more opportunities to interact with classmates and teacher and involve in class activities. It also can be seen from the improvement in "Teacher's Leading", students become more independent in learning process, which represents that their autonomous learning may be improved[17]. For class B, students' perception improvement in "classroom involvement" is the most and the improvement in "Equality" is the least, which shows that $50 \%$ of formative assessment reduced their pressure on final examination, so they are more willing to participate in classroom activities. However, they may fail to grasp opportunities to involve in class activities due to limited time in class and their relatively low English proficiency. From the t-score and p-value, we can see that the $50 \%$ formative assessment's influence difference between the two classes is significant on five factors, namely "Students' Cooperation", "Students' Collaboration", “ Students' Responsibility", "Equality" and "Teachers' innovation", which illustrates that class with higher English proficiency has more positive attitude to cooperation with classmates and is more capable of helping each other. In addition, as their autonomous learning ability improved, they have a more clear understanding of their responsibility and all kinds of tasks designed by teacher. As for the "Equality", students in Class A have higher English proficiency, so they can grasp more opportunity to involve in class activities and recognize the extraordinary arrangement of the class in this semester. In short, students in class A are more satisfied with the classroom environment after increasing the ratio of formative assessment.

Table 3. Influence Differences of different level students on Classroom Environment

\begin{tabular}{|c|c|c|c|c|c|c|c|c|c|c|c|c|}
\hline \multirow{3}{*}{\begin{tabular}{|l} 
Factors of \\
Classroom \\
Environment
\end{tabular}} & \multicolumn{3}{|c|}{ Mean } & \multicolumn{3}{|c|}{ Std. Deviation } & \multicolumn{6}{|c|}{$\begin{array}{l}\text { LSD Multiple Comparisons of Influence Difference } \\
\text { between Groups }\end{array}$} \\
\hline & & & & & & & Mea & an Differ & ence & & P value & \\
\hline & $\begin{array}{l}\text { High } \\
(n=11)\end{array}$ & \begin{tabular}{|l|} 
Medium \\
$(n=39)$
\end{tabular} & $\begin{array}{l}\text { Low } \\
(n=11)\end{array}$ & High & Medium & Low & $\begin{array}{l}\text { High-Me } \\
\text { dium }\end{array}$ & $\begin{array}{l}\text { High-L } \\
\text { ow }\end{array}$ & $\begin{array}{l}\text { Medium } \\
\text {-Low }\end{array}$ & $\begin{array}{l}\text { High-M } \\
\text { edium }\end{array}$ & $\begin{array}{l}\text { High-Lo } \\
\text { w }\end{array}$ & $\begin{array}{l}\text { Mediu } \\
\text { m-Low }\end{array}$ \\
\hline $\begin{array}{l}\text { Students' } \\
\text { Collaboration }\end{array}$ & .536 & .403 & .227 & .2846 & .2782 & .2287 & .1338 & $.3091^{*}$ & .1753 & .462 & .029 & .191 \\
\hline $\begin{array}{l}\text { Students' } \\
\text { Cooperation }\end{array}$ & .676 & .424 & -.014 & .4127 & .2180 & .2715 & $.2520 *$ & $.6900 *$ & $.4380 *$ & .025 & .000 & .000 \\
\hline $\begin{array}{l}\text { Teachers' } \\
\text { Support }\end{array}$ & .425 & .285 & .031 & .3098 & .2654 & .3198 & .1406 & $.3946^{*}$ & $.2540 *$ & .455 & .006 & .033 \\
\hline $\begin{array}{l}\text { Teachers' } \\
\text { Leading }\end{array}$ & .221 & .143 & -.064 & .1628 & .2404 & .2501 & .0781 & $.2846^{*}$ & $.2065^{*}$ & .977 & .016 & .033 \\
\hline \begin{tabular}{|l|} 
Classroom \\
Involvement
\end{tabular} & .695 & .391 & .169 & .3181 & .3016 & .3637 & $.3033^{*}$ & $.5255^{*}$ & .2222 & .020 & .001 & .132 \\
\hline $\begin{array}{l}\text { Students' } \\
\text { Responsibility }\end{array}$ & 0.390 & .304 & .012 & .3121 & .3661 & .2140 & .0856 & $.3782^{*}$ & $.2925^{*}$ & 1.000 & .032 & .040 \\
\hline $\begin{array}{l}\text { Task } \\
\text { Orientation }\end{array}$ & .655 & .349 & .082 & .3205 & .3300 & .1722 & $.3058^{*}$ & $.5727 *$ & $.2669 *$ & .015 & .000 & .041 \\
\hline Equality & .182 & .129 & -.050 & .2235 & .1963 & .1342 & .0526 & $.2318^{*}$ & $.1792 *$ & 1.000 & .019 & .025 \\
\hline $\begin{array}{l}\text { Teachers' } \\
\text { Innovation }\end{array}$ & .450 & .310 & -.090 & .5220 & .4680 & 3020 & .1470 & $.5450^{*}$ & $.3990 *$ & 1.000 & .020 & .038 \\
\hline
\end{tabular}

Individual Differences. According to the data in Table 3, from the mean, we can infer that the students with high and medium level English proficiency have improved on all factors after increasing the share of formative assessment to 50\%. For students with high English proficiency, 
their perception on "Classroom Involvement" is greater than any other factors; for the second group, their improvement in "Students' Cooperation" is the greatest; while for the third group, their improvement in "Students' Collaboration" is the most but their perception on "Students' Cooperation", "Teacher Leading" and "Equality" and "Teachers' Innovation" decreased slightly instead. The results show that students with better English proficiency can adapt themselves to this new assessment method and participate in all activities easily, while the students with a low English proficiency may find it a little difficult to involve in classroom activities because of their learning habits and knowledge level. To figure out the degree of their perception difference among these three groups, we conducted the LSD multiple comparisons of the influence differences.

From the below table, we can see that there are significant influence differences on all classroom environment factors among the three groups. The specific influence differences are: the influence of "Students' Cooperation" and "Task Orientation" of high level students is greater than that of medium level students, and they are both greater than that of low level students. Perception on “Teachers' Support", “Teacher's Leading”, "Student's Responsibility" ,"Equality", “Teachers' Innovation" of both high and medium level students is greater than that of the low level students. Improvement in "Classroom Involvement" of high level students is greater than that of medium and low level students, and there is not significant difference between the medium and low level students. The perception on "Students' Collaboration" and "Teachers' innovation" of high level students is significantly greater than that of low level students, there is no significant difference between medium level group and high level group or low level group respectively. It is clear that the influence of the high level group is significantly greater than that of the low-level group on all factors; the influence of the medium-level group is significantly greater than that of the low-level group except in "Students Collaboration" and "Classroom Involvement". The influence of high and medium-level group presents positive while the influence of low-level group is negative in "Students Cooperation"; "Teachers' Leading"; "Equality" and "Teachers' Innovation" . The result fully demonstrated that there are great individual differences between students of different levels. Students with higher English proficiency have a greater improvement in their perception of classroom environment. Because of different language proficiency, different learning ability, learning habits and personalities, their perception on classroom environment vary. The students with better English proficiency can grasp more chance to participate in class, cooperate with other students and have a better understanding of their tasks. While students with low English proficiency show negative perception in four factors, which indicates that they can't adapt themselves to this new teaching model in which they need to accomplish more tasks by themselves, to participate in class activities and cooperate with classmates, they are more willing to listen to teachers passively and can't recognize the innovative measures taken by teachers successfully. Therefore, teacher should pay more attention to them, for example, design the activities and tasks properly that suitable for all students; mobilize high and medium-level students to help them which is not only helpful to mutual development but also to their relationship.

Nterview Analysis. In order to have a better understanding of students' feeling about the classroom environment under 50\% formative assessment mode, we interviewed several students of different levels. Student A said that he enjoys this kind of classroom environment in which he has more opportunities to cooperate with others and to interact with peers and teachers. He is interested in the activities designed by teacher and is willing to participate in them. Students B thinks that her attitude towards English Reading, Writing, Translating class changed. The class is more interesting than that before. Before this semester, she just showed up in the class and listened to teachers passively, but now, she become more careful in class and after class because there are more tasks need to be accomplished by herself. She said "we can help each other or ask teacher for help when we have difficulties, it is helpful to improve our performance in class and our relationship between each other". Student $C$ thinks that the activities in class sometimes are a little difficult for him, he can't follow classmates' learning pace sometimes. But he likes this assessment mode, just as he said 
“ it reduced my pressure on the final examination, I can get scores during the learning process, and I am willing to participate in class activities and I will try my best if the assessment mode would continue next semester".

\section{Discussion}

By analyzing data, it is clear that students' perception to English Reading, Writing and Translating classroom environment has improved a lot. Their willing to participate in class activities, cooperate and interact with classmates are enhanced. The interview also shows that students are generally satisfied with this new assessment mode. There are many advantages of formative assessment to improve classroom environment as well as many problems after increasing the ratio of formative assessment to $50 \%$.

Fostering Students' Autonomous Learning Ability. The results show that students' perception of participation and task orientation has been improved a lot. During the process of finishing all tasks assigned by teacher, their autonomous learning ability has unconsciously been improved. Besides, they can have a clear mind of how well their performance is according to the feedback given by teachers. All these contributed to developing their autonomous learning ability[20].

Promoting Students' Awareness of Cooperation and Participating. Language learning is a social process in which people can acquire knowledge by communicating with others in a social context[21]. Under this new assessment mode, students can gain scores by accomplishing all kinds of tasks which can help building their awareness of helping each other and involving in classroom. This kind of assessment mode also reduced their anxieties about the final examination and aroused their interests because formative assessment is made according to their usual performance instead of the final examination. Therefore, they can enjoy the learning process. But there also exist some problems in low level group due to different personalities and language proficiency. Teachers should make students of different English proficiency as a group, so the high level students can help the low level students and then make progress together.

Giving Equal Chance to Students of Different English Proficiency. According to the result of quantitative analysis and interview, we can understand that students' perception to "Equality" didn't get much improvement, or even decreased for the low level students. It is advisable that teacher should pay more attention to those low level students by encouraging them to answering questions and involving them in all activities. The teacher can also design some tasks that are suitable for their English proficiency as a way to help building their confidence. As their confidence grows, they can become more active in class.

\section{Conclusion}

An effective classroom environment is vital to improve teaching quality[22], so it is of great significance to study the way of building a effective classroom environment. The present paper studied the influence of 50\% formative assessment on English Reading, Writing, Translating class. The results show that students' overall perception on the classroom environment of English Reading, Writing, Translating class have improved greatly, which indicates that the $50 \%$ formative assessment has a positive impact on the classroom environment. But there are also some problems, so suggestions are put forward for better implementing formative assessment mode. However, there are several limitations in this study as well, namely, limited experiment time and sample size; neglect of the influence difference between different genders. Therefore, the following study can increase the sample size which covers different major students to explore the gender difference in a relatively long period of time.

\section{Acknowledgements}

Teaching research project of Hubei Provincial Department of Education: "College English Reading, Writing and Translating Classroom Environment Research" (No. 2012230) 


\section{References}

[1]. J.G. Cai: Foreign Language World, (2011) No.1,p.21-29.(In Chinese)

[2]. T.T Liu: Heilongjiang Researches on Higher Education, (2014)No.12,p.167-169.(In Chinese)

[3]. Fraser, B.J. Classroom Environment. London: Croom Helm, 1986,p.5-8.

[4]. Y.M.Sun: Foreign Language Teaching and Research(bimonthly),Vol.42 (2010),No.6,p.438-444.(In Chinese)

[5]. Haertel, G.D. and Walberg, H.J.\& Haertel, E.H. Socio-Psychological Environments and Learning: A Quantitative Synthesis. British Educational Research Journal, 1981,(7):27-36.

[6]. Majeed, A. and Fraser, B.J. \& Aldridge, J.M. Learning Environment and Its Association with Student Satisfaction Among Mathematics Students in Brunie Darussalam. Learning Environment Research, 2002,(5):203-226.

[7]. Baek, S. G. and Choi, H.J. The relationship between Students' Perception of Classroom Environment and Their Academic achievement in Korea. Asia Pacific Education Review, 2002, (3):125-135.

[8]. Z.Y. Qu: Studies in Foreign Education, Vol.29(2002), No.7,p.21-25.(In Chinese)

[9]. Q.H. Zhao and J.F.Xu: Foreign Languages And Their Teaching,Vol.265(2012),No.4,p.66-74. (In Chinese)

[10]. L.Y.Liu and Y.B.Liu: Foreign Language Learning Theory and Practice,2012,No.4, p76-82.(In Chinese)

[11]. G.F.Li and L.H.Liu: Theory and Practice of Education,Vol.35(2015),No.3,p 4-51.(In Chinese)

[12]. L.He and G.S.Lu and H.B.Li: Theory and Practice of Comtemporary Education, Vol.8(2016),No.6, p88-91.(In Chinese)

[13]. C.L.Fan and Q. Dong: Comparative Education Review, Vol.8(2005), No.8, p62-66.(In Chinese)

[14]. S.L.Yu and J.Y.Han and J.J.Wang: Foreign Language World, 2012,No.1, p27-34.(In Chinese)

[15]. Harlen. W and James M. Assessment and Learning: Differences and relationships between formative and summative assessment, Assessment in Education. 1997.

[16]. Genesee. F and J. Upshur. Classroom-based Evaluation in Second Language Education. Canbridge. University Press.1996.

[17]. Q.Guo: Journal of Xi'an International Studies University, Vol.12(2004),No.2,p66-68.(In Chinese)

[18]. Q.F.Wen: Foreign Language Testing and Teaching, 2011,No.3,p39-49.(In Chinese)

[19]. R.P.Cao and Y.P.Chen: Chinese Translators Journal, 2013,No.1,p45-50.(In Chinese)

[20]. Fraser,B.J and Fisher, D.L \& McRobbie,C.J: Development, Volidation, and Use of Personal and Class Forms at the New Classroom Environment[R]. Paper presented at the Annual Meeting of the American Educational Research Association, New York,1996.

[21]. M.Y.Shen: Journal of Tianjin Foreign Studies University,Vol.17(2010),No.2 p76.(In Chinese)

[22]. Wertsch J.V, A Sociocultural Approach to Mediated Action. Oxford: Havard Univesity Press.1991.

[23]. Q.M.Ren: Foreign Language Teaching and

Research(bimonthly),Vol.45(2013),No.5,p732-743.(In Chinese) 